\title{
Is sparing the prostate still considered radical cystectomy? The case against prostate-sparing cystectomy for bladder cancer
}

\author{
Ahmed Kotb, MD; Armen G. Aprikian, MD, FRCSC
}

Can Urol Assoc J 2009;3(Supp|4):S220-2

$\mathrm{R}$ adical cystoprostatectomy with bilateral pelvic lymphadenectomy and urinary diversion remains the gold standard therapy for localized bladder cancer in men. ${ }^{1}$ The procedure has been refined over several decades with the current application of nerve-sparing techniques..$^{2,3}$ Unfortunately, the procedure carries significant risks of urinary and sexual dysfunction resulting in bladder-sparing approaches being popularized for selected early invasive bladder cancers. More recently, some authors have suggested that prostate-sparing cystectomy may be appropriate in selected men to improve postoperative sexual and urinary function. ${ }^{4-6}$ They propose that leaving the prostate, or part of it, intact will result in less damage to pelvic innervation and better preservation of sexual function and urinary sphincter control in cases of orthotopic diversion. These potential functional improvements must be weighed against any risks for oncologic outcomes.

One potential oncologic pitfall is the assumption that the prostate does not harbour transitional cell carcinoma (TCC) of the bladder. The incidence of occult prostatic involvement with TCC in patients undergoing radical cystectomy ranges between $20 \%$ and $48 \%,{ }^{7-9}$ raising significant concern about sparing the prostate. In a large study, Pettus and colleagues ${ }^{10}$ concluded that patients with tumours involving the trigone and bladder neck or associated carcinoma in situ of the bladder should be considered at high risk for developing prostatic urethral carcinoma. Moreover, the absence of these factors did not conclusively rule out the presence of carcinoma in the prostatic urethra.

Another significant risk is the potential for prostatic adenocarcinoma. Many argue that prostate cancer is not a major problem in this population, since men undergoing cystectomy for invasive bladder cancer are often elderly, with a poor prognosis for their bladder cancer. However, prostatesparing surgery is usually offered to men whose pelvic disease is not advanced and in whom sexual function is normal, thus younger men. It is precisely in these younger men with early forms of invasive bladder cancer that occult prostate cancer could pose problems in the future. Occult prostate cancer has a reported incidence of $23 \%$ to $47 \%$ in men undergoing radical cystectomy. Furthermore, about 50\% of these cancers are potentially significant based on histologic criteria. ${ }^{11-14}$ Revelo and colleagues ${ }^{11}$ detected that $41 \%$ of cases had unsuspected prostatic cancer, of which $48 \%$ were clinically significant and $16 \%$ were extracapsular. Of importance, $60 \%$ involved the apex, including $79 \%$ of significant cases, suggesting that recommending apical sparing as a compromise could potentially be equally hazardous.

These findings were confirmed by another study in which $27 \%$ of patients undergoing cystectomy for invasive TCC of the bladder were found to have prostatic carcinoma (PCa), with $33 \%$ involving the apex of the prostate. ${ }^{15}$ The authors suggested that the high likelihood of apical prostate cancer requires careful excision of the apical margins. Kablain and colleagues ${ }^{13}$ previously reported that $38 \%$ of patients undergoing cystectomy for bladder cancer and who harbour prostate carcinoma had a distinct apical predominance of the tumours.

In a recent study, Hautmann and colleagues ${ }^{16}$ addressed the probability of overlooking clinically significant prostate cancer using sextant biopsy. They analyzed specimens from 133 consecutive patients undergoing cystoprostatectomy for bladder cancer. Patients were included in the study if they had serum prostate-specific antigen (PSA) $<4 \mathrm{ng} / \mathrm{mL}$, normal digital rectal exam and free-PSA $>25 \%$. Systematic sextant biopsy was performed in the operating room immediately following cystoprostatectomy and prostates were subsequently step-sectioned $(3 \mathrm{~mm})$. The threshold defined to distinguish between significant and insignificant cancer was $0.5 \mathrm{~cm}^{3}$. Incidental prostatic cancer was found in 58 of the 133 bladder cancer patients (44\%), with presence of significant cancer in many. Sextant biopsy detected 7 cancers, including 4 of 47 (9\%) that were insignificant and 3 of $11(27 \%)$ that were significant. Thus, sextant biopsy missed $8(73 \%)$ of 11 of significant prostate cancers. These data suggest that despite careful screening for prostate cancer for cystoprostatectomy patients, it remains regularly overlooked in a significant proportion of clinically relevant cases.

In a recent prospective study by Saad and colleagues, ${ }^{17}$ 425 men had radical cystoprostatectomy for invasive bladder cancer and entire mounted prostates were step-sectioned at 2 to $3 \mathrm{~mm}$ intervals. Of 425 cases examined, there was 
The case against prostate capsule-sparing radical cystectomy

histological evidence of prostatic adenocarcinoma in 90 cases $(21.2 \%)$. Prostatic TCC was found in 66 patients (15.6\%). There was also significant benign prostatic hyperplasia in 175 (41.2\%). They concluded that the marginal reported functional advantage of prostate-sparing cystectomy is not worth the potential oncological risks.

In a prospective study, Koraitim and colleagues ${ }^{18}$ studied urinary continence and voiding differences between men undergoing classic radical cystoprostatectomy and men with prostate-sparing cystectomy. They found no statistical difference between both groups with respect to urinary continence, but found a significant difference in peak flow rate. They concluded that preservation of prostatic apex may present an element obstructing the evacuation of ileal bladders.

\section{Oncological outcomes}

Several studies have suggested that oncological outcomes may be compromised when prostate-sparing cystectomy is performed. Saidi and colleagues ${ }^{19}$ reported 25 cases with a median follow-up of 46 months. All patients had serum PSA $<4 \mathrm{ng} / \mathrm{mL}$ or negative needle biopsy and transurethral resection of the prostate performed preoperatively to evaluate prostatic urethra. Surprisingly, $24 \%$ developed a pelvic recurrence, $8 \%$ a urethral recurrence and $24 \%$ distant metastases. The authors concluded the oncologic outcome was worse than the results of standard radical cystoprostatectomy. These findings are supported by a review that evaluated oncological results following 3 different prostate-sparing techniques. ${ }^{20}$ The authors concluded that preservation of the prostate may improve functional results; however, it does not appear to ensure an equivalent level of cancer control and has higher recurrence rates.

The primary goal of prostate-sparing cystectomy is to optimize postoperative functional results for continence, potency and, perhaps, fertility. The continence rate for prostatesparing cystectomy in most series is excellent. ${ }^{4-6,21-27}$ Of 10 series, 9 reported daytime continence rates of at least $94 \%$. Nighttime continence rates were at least $94 \%$ in 6 series and all but 1 reported rates greater than $77 \%$. However, some authors demonstrated near-equal continence rates using classic radical cystoprostatectomy with nerve-sparing technique with the incidence of daytime and nighttime continence of $90 \%$ to $95 \%$ and $80 \%$, respectively. Studies using validated questionnaires, such as by Steers and colleagues, noted daytime and nighttime continence rates of $87 \%$ and $72 \%$, respectively, in 2238 patients. ${ }^{28,29}$

With respect to potency, prostate-sparing procedures do provide somewhat better results; however, the application of nerve-sparing approaches in selected individuals and the use of oral and injectable therapies have improved the potency outcomes of men undergoing standard cystoprostatectomy.

\section{Conclusion}

Radical cystoprostatectomy remains the gold standard treatment for invasive bladder cancers and appears to have better oncological outcomes. The application of nerve-sparing techniques in selected patients can result in improved functional results in continence and potency without jeopardizing oncological outcome. Though prostate sparing cystectomy may provide a somewhat better functional outcome, it carries a significant risk of poor oncological outcome, especially given the current inability to exclude prostatic involvement with certainty either by transitional cell carcinoma or adenocarcinoma.

McGill University Health Centre, McGill University, Montréal, QC

Competing interests: None declared.

This paper has been peer-reviewed.

\section{References}

1. Dinney CP. Therapy of invasive bladder cancer. Urology 2006;67:56-9.

2. Kessler TM, Burkhard FC, Perimenis $P$, et al. Attempted nerve sparing surgery and age have a significant effect on urinary continence and erectile function after radical cystoprostatectomy and ileal orthotopic bladder substitution. J Urol 2004;172:1323-7.

3. Schoenberg MP, Walsh PC, Breazeale DR, et al. Local recurrence and survival following nerve sparing radical cystoprostatectomy for bladder cancer: 10 year follow up. J Urol 1996;155:490-4.

4. Vallancien G, Abou El Fettouh H, Cathelineau X, et al. Cystectomy with prostate sparing for bladder cancer in 100 patients: 10 year experience. J Urol 2002;168:2413-7.

5. Muto $G$, Bardari F, D'Urso $L$, et al. Seminal sparing cystectomy and ileocapsuloplasty: Iong term followup results. J Urol 2004;172:76-80.

6. Botto H, Sebe P, Molinie V, et al. Prostatic capsule and seminal sparing cystectomy for bladder carcinoma: initial results for selected patients. BJU Int 2004;94:1021-5.

7. Hassan JM, Cookson MS, Smith JA, et al. Patterns of initial transitional cell recurrence in patients after cystectomy. J Urol 2006;175:2054-7.

8. Greven KM, Spera JA, Solin L, et al. Local recurrence after cystectomy alone for bladder carcinoma. Cancer 1992;69:2767-70.

9. Visser D, Niewenhuijzen JA, Horenblas J. Local recurrence after cystectomy and survival of patients with bladder cancer; a population based study in greater Amsterdam. J Urol 2005;17:97-102.

10. Pettus JA, Al-Ahmadie H, Barocas DA, et al. Risk assessment of prostatic pathology in patients undergoing radical cystoprostatectomy. Eur Urol 2008:53:370-5

11. Revelo MP, Cookson MS, Chang SS, et al. Incidence and location of prostate and urothelial carcinoma in prostates from cystoprostatectomies: Implications for possible apical sparing surgery. J Urol 2004; 171:646-9

12. Pettus JA, Al-Ahmadie H, Barocas DA, et al. Prostate involvement by urothelial and prostatic carcinomas in radical cystoprostatectomy specimens. Paper presented at: The 2006 Annual Meeting of the American Urological Association, May 20-25, 2006; Atlanta, GA.

13. Kabalin JN, McNeal JE, Price HM, et al. Unsuspected adenocarcinoma of the prostate in patients undergoing cystoprostatectomy for other causes: incidence, histology and morphometric observations. J Urol 1989; 141:1091-4.

14. Moutzouris G, Barbatis C, Plastiras D,et al. Incidence and histological findings of unsuspected prostatic adenocarcinoma in radical cystoprostatectomy for transitional cell carcinoma of the bladder. Scand J Urol Nephrol 1999;33:27-30.

15. Weizer AZ, Shah RB, Gilbert SB, et al. Presence, location and significance of prostate cancer in patients undergoing radical cystoprostatectomy: Feasibility of prostate-capsule sparing cystectomy. Paper presented at: The 2006 Annual Meeting of the American Urological Association, May 20-25, 2006; Atlanta, GA. 
Kotb and Aprikian

16. Hautmann $\mathrm{S}$, Conrad $\mathrm{S}$, Henke RP, et al. Detection rate of histologically insignificant prostate cance with systemic sextant biopsies and fine needle aspiration cytology. J Urol 2000;6:1734-8.

17. Saad M, Abdel-Rahim M, Abol-Enein H, et al. Concomitant pathology in the prostate in cystoprostatectomy specimens: a prospective study and review. BJU Int 2008;102:1544-50.

18. Koraitim MM, Atta MA, Foda MK. Impact of the prostatic apex on continence and urinary flow in patients with intestinal neobladder. Br J Urol 1996;78:534-6.

19. Saidi A, Nahon 0 , Daniel L, et al. Prostate sparing cystectomy: Iong term functional and oncological results in a series of 25 cases. Prog Urol 2004; 14:172-7.

20. Sebe P, Traxer 0, Cussenot 0, et al. Cystectomy with preservation of the prostate in the treatment of bladder tumours: Anatomical basis, surgical techniques, indications and results. Prog Urol 2003;13:1279-85.

21. Schlegel PN, Walsh PC. Neuroanatomical approach to radical cystectomy with preservation of sexua function. J Urol 1987;138:1402-6.

22. Colombo R, Bertini R, Salonia A, et al. Overall clinical outcomes after nerve and seminal sparing radical cystectomy for the treatment of organ confined bladder cancer. J Urol 2004;171:1819-22.

23. Terrone C, Cracco C, Scarpa RM, et al. Supra-ampullary cystectomy with preservation of sexual function and ileal orthotopic reservoir for bladder tumour: twenty years of experience. Eur Urol 2004;46:264-70.
24. Martis GD, Elia G, Diana $M$, et al. Prostatic capsule and nerve sparing cystectomy in organ confined bladder cancer: preliminary results. World J Surg 2005;29:1277-81.

25. Arroyo C, Andrews H, Rozet F, et al. Laparoscopic prostate sparing radical cystectomy: the Montsouris technique and preliminary results. J Endourol 2005; 19:424-8.

26. Wunderlich $H$, Wolf $M$, Reichelt 0 , et al. Radical cystectomy with ultrasound guided partial prostatectomy for bladder cancer: a complication preventing concept. Urology 2006;68:554-9.

27. Abuzeid AM, Saleem MD, Badawy AA, et al. Genital sparing radical cystectomy for organ confined bladder carcinoma. Impact on tumor control and quality of life. J Urol 2005;173A:05-AB-4215-AUA.

28. Mansson A, Davidson A, Hunt $\mathrm{S}$, et al. The quality of life in men after radical cystectomy with a continent cutaneous diversion or orthotopic bladder substitution: is there a difference? BJU Int 2002;90:386-90.

29. Steers WD. Orthotopic neobladder: functional outcomes. World I Urol 2000;18:330-7.

Correspondence: Dr. Armen Aprikian, Professor and Head, Division of Urology, McGill University, Urologist-in-Chief, McGill University Health Centre, Director, Department of Oncology, McGill University Health Centre, 1650 Cedar Avenue, Montréal, QC H3G 1A4; armen.aprikian@mnhc.mcgill.ca 